\title{
Monitoring porcine reproductive and respiratory syndrome virus infection status in swine herds based on analysis of antibodies in meat juice samples
}

\author{
Sten MorTENSEN ${ }^{\mathrm{a} *}$, Bertel STRANDBYGAARD ${ }^{\mathrm{b}}$, Anette B $\varnothing$ TNER $^{\mathrm{b}}$, \\ Niels FELD ${ }^{\mathrm{c}}$, Preben WILLEBERG ${ }^{\mathrm{a}}$

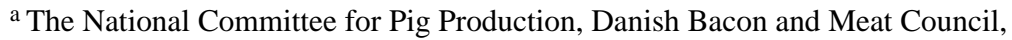 \\ Veterinary and Food Advisory Service, Axeltorv 3, DK-1609 Copenhagen V, Denmark \\ ${ }^{\mathrm{b}}$ Danish Veterinary Institute for Virus Research, Lindholm, DK-4771 Kalvehave, Denmark \\ ${ }^{\mathrm{c}}$ Danish Veterinary Laboratory, DK-1790 Copenhagen V, Denmark
}

(Received 8 June 2000; accepted 3 April 2001)

\begin{abstract}
An indirect ELISA test was developed as a novel tool aimed at monitoring the herd infection status of swine herds. Meat juice samples from pig carcasses were analysed for the presence of antibodies against porcine reproductive and respiratory syndrome virus (PRRSV). A study of samples from herds with known PRRS status was undertaken. The PRRS status of the herds was evaluated based on the analysis of blood samples by another serological test (blocking ELISA) capable of differentiating between infection with PRRSV of the American type and European type. The specificity of the indirect ELISA test on meat juice samples was 0.98. The sensitivity of the test depended on the type of the PRRSV strain involved. The apparent prevalence in herds infected with the American type of PRRSV was 0.44. The apparent prevalence in herds infected with the European type of PRRSV was 0.64. Herd level sampling and herd level criteria for assessing the PRRS status of herds by the new test were developed. Herds were classified as PRRS negative or PRRS seropositive based on 10 meat juice samples collected randomly at slaughter throughout a 3-month-period. Herd PRRS status classification by the indirect ELISA was validated in 47 herds by collection of blood samples from the herds. Eighteen herds were classified as PRRS negative by both test systems. Twenty-nine herds were classified as PRRS seropositive by both test systems. Acceptable herd classification was achieved using this test.
\end{abstract}

ELISA / PRRSV / sensitivity /specificity / herd-level / meat juice

* Correspondence and reprints

Phone: (45) 337325 94; fax: (45) 331457 56; e-mail: sm@danishmeat.dk 
Résumé - Surveillance du statut d'infection par le virus du syndrome dysgénésique et respiratoire porcin dans des élevages, basée sur la détermination de la présence d'anticorps dans des échantillons de jus de viande. Un test ELISA indirect a été développé pour déterminer la présence d'anticorps contre le virus du syndrome dysgénésique et respiratoire porcin (PRRSV) dans des échantillons de jus de viande provenant de carcasses de porc afin de connaître le statut d'infection par le PRRSV des élevages porcins. L'étude d'élevages ayant un statut sanitaire positif connu a été entreprise. Le statut d'infection par le PRRSV a été évalué par une autre méthode d'analyse (ELISA bloquant) d'échantillons sanguins permettant de faire la différence entre une infection par les souches américaine et européenne du PRRSV. La spécificité de l'ELISA indirect sur les échantillons de jus de viande fut de 0,98. La sensibilité du test dépendait de la souche de PRRSV. La prévalence apparente dans les élevages infectés par la souche américaine de PRRSV fut de 0,44. La prévalence apparente dans les élevages infectés par la souche européenne de PRRSV fut de 0,64. Une méthode d'échantillonnage et des critères permettant d'évaluer le statut d'infection par le PRRSV des élevages par le test ELISA indirect ont été déterminés. Les élevages ont été classés séropositifs ou séronégatifs vis-à-vis du PRRSV grâce à l'analyse de 10 échantillons de jus de viande prélevés au hasard à l'abattoir durant une période de 3 mois. La classification du statut d'infection des élevages par le PRRSV obtenue par le test ELISA indirect a été validée dans 47 élevages grâce à la collecte d'échantillons sanguins. Dix-huit élevages ont été déterminés négatifs au PRRSV par les deux méthodes. Vingtneuf élevages ont été déterminés séropositifs au PRRSV par les deux méthodes. Une classification acceptable des élevages a pu être obtenue en utilisant ce test.

ELISA / virus du syndrome dysgénésique et respiratoire porcin / sensibilité / spécificité / test en élevage / jus de viande

\section{INTRODUCTION}

Porcine Reproductive and Respiratory Syndrome virus (PRRSV) has become a significant cause of production losses in most swine producing countries. Correct classification of the herd infection status is a prerequisite for choosing preventive measures against production losses. In non-infected herds, the most important prophylactic measure against the disease is to prevent infection by quarantine of replacement breeding stock and assure the non-infected status of the animals by serological tests. In infected herds other management techniques may be required to reduce virus circulation within the herds $[4,7]$. The swine industry in Denmark has initiated a PRRS certification scheme to reduce the dissemination of the virus by trade of animals between herds of dissimilar infection status. Existing techniques for these purposes are based on the collection of blood samples in herds at regular intervals with subsequent serological analyses of the sera.

Recent advances in techniques for herd infection status monitoring include the development of serological assays for the detection of antibodies in muscle fluid obtained when a meat sample is thawed [5, 12]. This method is used to monitor the salmonella level in herds producing slaughter pigs in Denmark [9]. Diagnostic assays for swine diseases used with meat samples have potential benefits because the collection of sample material at the slaughterhouse can be automated and therefore demands less resources than blood sample collection in herds. These developments have been facilitated by the installation of computer networks at the slaughter line that allow the specification of flexible per-herd sampling plans for identification of carcasses for sampling. Another benefit of the system is the continuous monitoring of the herd infection status rather than monitoring on an (e.g.) annual basis. This is achieved by sampling every $n$th animal shipped for slaughter throughout the year.

An indirect ELISA assay was developed to search for antibodies against PRRSV in the meat juice. The objective of the studies in this paper was to assess the quality of the 
herd level testing for PRRSV infections with the meat sampling technique.

\section{MATERIALS AND METHODS}

Four studies were undertaken: in study 1 , serum samples and meat juice samples from individual pigs were used to assess the sensitivity and the specificity of the new test (indirect ELISA). In study 2, meat juice samples from infected herds and noninfected herds were used to estimate apparent within-herd prevalence. In study 3 , the herd level sensitivity, the herd level specificity and the herd level predictive values of the testing procedure were assessed. In study 4, the herd PRRS infection status was validated.

\subsection{Serological assays}

Based on antigenic differences, PRRS viruses can be divided into 2 types: an American (PRRS-US) type and a European type (PRRS-EU) $[10,11]$. It is possible to distinguish between herds infected with respectively the American and the European type of PRRSV by means of serological analysis of blood samples using blocking ELISAs or immunoperoxidase monolayer assays (IPMAs) [8, 13, 14]. Both types of PRRSV are prevalent in the Danish swine population [3]. The presence of the American strain is due to the use of a modified live vaccine based on the American isolate VR2332. Consequently, the herd infection status with regards to PRRS types in a Danish herd may be one of four: non-infected, PRRS-US infected (and PRRS-EU noninfected), PRRS-EU infected (and PRRSUS non-infected) or double infected. The PRRS assay used for meat juice analysis was an indirect ELISA [1] with mixed antigens of both PRRSV types aimed at detecting both types of PRRSV without discriminating between them. The test was prepared according to Albina et al. [1] with the major exceptions that antigens were grown in Marc cells and the meat juice samples were incubated at room temperature for one hour. A positive control sample was included in the test to calculate a sample-to-positive ratio (S/P) of optical densities. If the S/P ratio was $>0.3$, the sample was considered to be antibody positive. The indirect ELISA assay was run at the Danish Veterinary Laboratory (DVL).

\subsection{Test sensitivity and test specificity (study 1)}

A panel of paired sera and meat samples (see below) were obtained from slaughter pigs at a slaughter plant. The pigs originated from herds with known infection statuses. We obtained samples from one PRRS-EU infected herd, 2 PRRS-US infected herds, 2 double infected herds and 9 PRRS noninfected herds. The samples were used to estimate the test specificity and test sensitivity. The blocking ELISA test result [13] in serum was used as the "gold standard" for the meat juice test result of the same pig. The exact $95 \%$ confidence intervals (C.I.s) for the estimates were calculated from the binomial distribution.

\subsection{Identification of carcasses for sampling}

The Danish Bacon and Meat Council (DBMC) decided that sample analysis costs of PRRS monitoring in a herd by the new system should be similar to a yearly PRRS herd test based on serological analysis of 20 blood samples. A total of 40 meat samples per year was therefore the predefined per-herd sample size of the system. The PRRS herd register at the DBMC stores PRRS diagnostic results from herds in Denmark. The PRRS herd register was extended to generate herd specific sampling proportions based on the count of slaughtered pigs in the preceding 13 weeks. The system 
calculated what proportion of slaughtered pigs from a herd should be sampled to reach approximately 40 samples per year. The files of herd specific proportions were then electronically transferred to computers at the slaughter lines in all cooperative slaughter plants. These computers then identified every $n$-th pigs from a herd for sampling $(1 / n=$ the herd specific sampling proportion) and returned the sample information to the PRRS herd register, which in turn automatically adjusted sampling proportions according to the results of previous samples (see below), changes over time of the number of pigs slaughtered from a herd and the number of carcasses already identified for sampling. Upon identification of a carcass for sampling, a meat sample of one cubic centimetre was cut from the sternomastoideus muscle, placed in a test veil, identified, frozen and sent to the DVL for analysis.

\subsection{Apparent within-herd PRRS prevalence based on the indirect ELISA meat sample test (study 2)}

The PRRS herd register was used to identify herds with different PRRSV type infection statuses. Based on serological herd tests performed in 1997, 70 herds were selected for the study. A herd test denoted a set of at least 20 blood samples collected from all age groups in a herd. The blood samples were tested in blocking ELISAs or IPMAs that can discriminate the herd PRRSV type infection status [8]. We identified 27 PRRS non-infected herds (no positives among 20 blood samples), 11 PRRS-EU infected herds, 15 PRRS-US infected herds and 17 double infected herds. We then collected meat samples from approximately $5 \%$ of finisher pigs shipped to slaughter from these herds during the period from December 1997 to February 1998 and analysed the meat juice samples by the indirect ELISA. Herd infection status and PRRSV type (American or European) was confirmed by herd tests done in 1998, that is, after the completion of sample collection for study 2 .

The exact $95 \%$ confidence intervals for the within-herd prevalence estimates were calculated from the binomial distribution. We tested for over-dispersion of within-herd prevalences by the standard test of homogeneity of binomial observations [2].

\subsection{Probability assessment of the herd infection status assignment of the meat sample system (study 3 )}

The meat sample system was designed for monitoring the absence of infection in

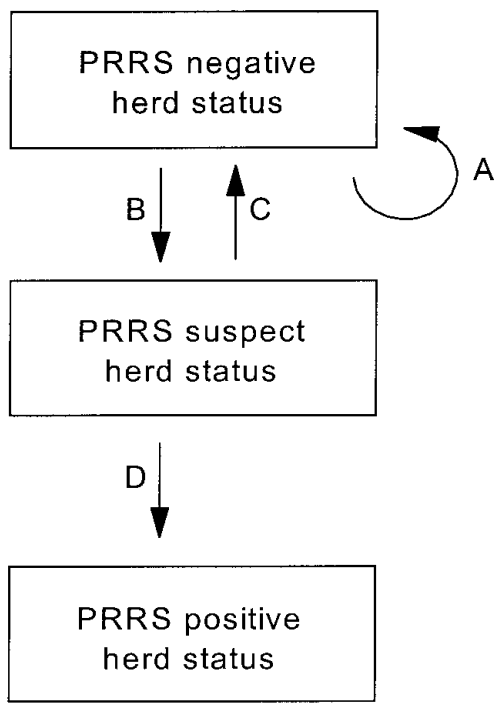

Figure 1. A model for change in PRRS herd infection status based on meat sample test results. Meat samples from every $n$th carcass from a herd were obtained at a rate of 40 samples per year. A: At zero or one positive samples in the latest sequence of 10 samples, the herd maintains its PRRS negative status. B: The herd status changed from PRRS negative to PRRS suspect if 2 samples in the latest sequence of 10 samples tested positive. C: Upon assignment of PRRS suspect status to a herd, 10 additional samples were collected within two weeks. At zero or one positive samples the herd regained PRRS negative status. D: At two or more positive samples, the herd was assigned PRRS positive status. 
PRRS negative herds. A simple model for the changes in herd infection status based on meat sample test results was developed (Fig. 1). According to the model, a PRRS negative herd would change status to "PRRS suspect" as soon as 2 samples among the sequence of 10 samples were positive. If zero or one sample tested positive, the PRRS negative status was renewed. If a herd changed status to PRRS suspect, ten $a d d i$ tional carcasses from the herd were identified for sampling within the next two weeks to clarify the infection status of the herd. At zero or one positive samples among the additional samples, the herd regained a PRRS negative status. Otherwise (two or more positive samples) the herd was assigned a PRRS positive status.

Based on the proportions of positive samples (apparent prevalences) in respectively PRRS negative herds and PRRS infected herds from study 2 , we calculated the probabilities of true and false classifications of infected herds as well as uninfected herds. The test specificity and sensitivity and the true prevalence in infected herds were not a prerequisite for these calculations. By means of formulas [6] we calculated the probability of assigning PRRS suspect status to respectively PRRS non-infected herds and true PRRS positive herds on the basis of 10 samples analysed per herd over a 3-month-period. The probability of assigning PRRS suspect status in a PRRS negative herd was approximated by the binomial probability of two or more positive samples among 10 samples with the probability of each sample being positive equal to the apparent prevalence in non-infected herds of study 2 . The probability of assigning PRRS suspect status in a PRRS positive herd was approximated by the binomial probability of two or more positive samples among 10 samples with the probability of each sample being positive equal to the lowest apparent prevalence among the groups of PRRSV infected herds in study 2 . We then calculated the probability of assigning PRRS negative status to true PRRS negative herds (herd-level specificity) as one minus the probability of PRRS suspect status in a PRRS negative herd times the probability of PRRS positive status in the 10 additional samples. The probability of PRRS positive status in an infected herd (herd-level sensitivity)

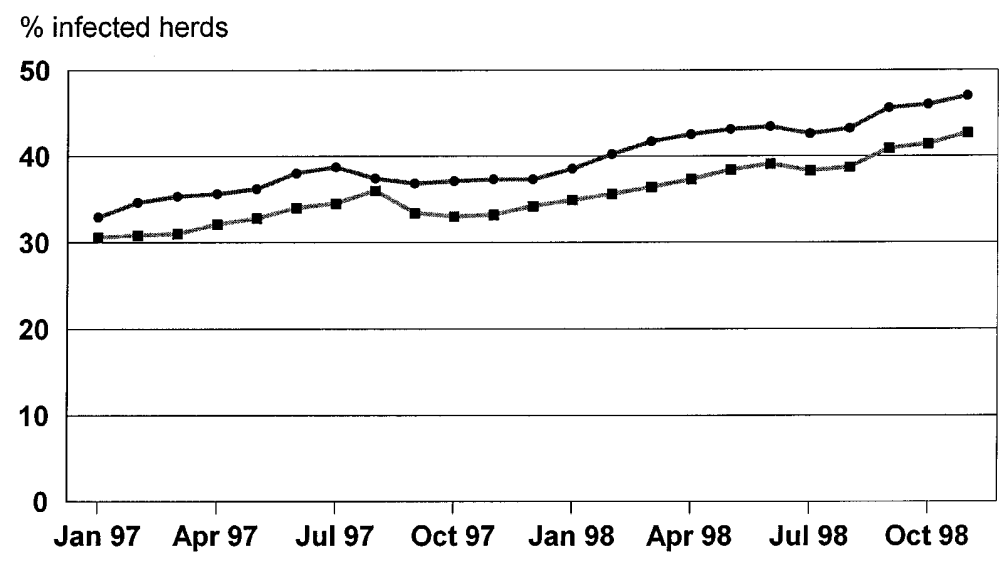

Figure 2. PRRS prevalence in approximately 4000 Danish sow herds (ם) and 2000 finishing pig herds (O) in 1997 and 1998. These herds housed $80 \%$ and 60\% of the national sow and finishing pig populations, respectively. The herd prevalence in sow herds increased from $31 \%$ to $43 \%$ and from $34 \%$ to $47 \%$ in finishing pig herds during the period. 
was calculated as the probability of a PRRS suspect status in a PRRS positive herd times the probability of PRRS positive status in the 10 additional samples. Furthermore we calculated the herd-level predictive values using the probabilities developed above (i.e. the probability of infection in a herd with a positive test result), knowing that 2000 PRRS negative herds used the system and assuming a herd incidence of $2 \%$ per 3 months (40 newly infected herds). Two percent were chosen because this was the national estimate of the mean incidence rate during a 3-month period in PRRS negative herds (Fig. 2). The exact 95\% confidence intervals for the predictive values were calculated from the binomial distribution.

\subsection{Validation of the meat sample system's PRRS status assignment (study 4)}

To validate the assignment of PRRS status to herds based on the meat sample test, a follow-up study was carried out. Approximately 2000 PRRS negative herds were monitored by this system in 1998. All herds that were assigned a "PRRS suspect" status by the system from January 1998 to May 1998 were asked to participate. The herds were followed up by collection of a minimum of 20 blood samples (stratified on all age-groups in the herd) and at the same time continued the meat sample monitoring until they were assigned PRRS negative or PRRS positive status. The study objectives were to compare the meat sample systems classification of herds with blood samples, the predictive values of herd classifications with the expected values from study 3 , and test specificity and the proportion of positive samples from infected herds with the results of study 2 . The exact $95 \%$ confidence intervals for the within-herd prevalence estimates were calculated from the binomial distribution.

\section{RESULTS}

\subsection{Test sensitivity and test specificity (study 1)}

The blocking ELISA test result in serum was used as the gold standard for the test result in the new meat juice test. Antibodies in serum were detected in all pigs from PRRS infected herds and in none of the pigs from non-infected herds. The test specificity of the new test was estimated at 0.96. The test sensitivities were estimated at $0.69,0.57$ and 0.75 , depending on the type of PRRS infection (Tab. I).

\subsection{Apparent within-herd PRRS prevalence based on the meat sample test (study 2)}

From 27 PRRS negative herds, 2.0\% (false) positive samples were found among 510 samples. This corresponded to a test specificity of 0.98 (C.I.: 0.96-0.99). In infected herds $64 \%, 44 \%$ and $56 \%$ positive samples were recovered in 11 PRRS-EU infected herds, 15 PRRS-US infected herds and 17 herds infected with both PRRS types, respectively (Tab. II). Ranges of withinherd prevalences in herds tested by more than 5 samples were $0.36-0.92,0.14-0.67$ and 0.23-0.78. In PRRS-EU infected herds and in double infected herds, the withinherd prevalences varied more than predicted by a binomial model $(p=0.005 ; p=0.005)$.

\subsection{Probability assessment of the PRRS status assignment of the meat sample system (study 3)}

The probabilities of assigning a PRRS suspect status to PRRS infected and PRRS negative herds based on 10 samples were $97.3 \%$ and $1.6 \%$ respectively (Tab. III). The probability of assigning a PRRS positive status to a PRRS infected herd was $94.7 \%$ (Tab. IV). The lower and upper values of 
Table I. Blocking ELISA test results in serum samples and indirect ELISA test results in meat juice samples from individual pigs (study 1).

\begin{tabular}{lcccc}
\hline Herd infection status & $\begin{array}{c}\text { Number of } \\
\text { pigs }\end{array}$ & $\begin{array}{c}\text { Number of } \\
\text { blocking ELISA } \\
\text { positive serum } \\
\text { samples }\end{array}$ & $\begin{array}{c}\text { Number of } \\
\text { indirect ELISA } \\
\text { positive meat } \\
\text { juice samples }\end{array}$ & $\begin{array}{c}\text { Specificity } \\
\text { or sensitivity } \\
\left(95 \% \text { C.I. }{ }^{b}\right.\end{array}$ \\
\hline $\begin{array}{l}\text { PRRS non-infected } \\
\text { (9 herds) }\end{array}$ & 187 & 0 & 8 & $\begin{array}{c}\text { Specificity } \\
0.96\end{array}$ \\
$\begin{array}{l}\text { PRRS-EU infected } \\
(1 \text { herd) }\end{array}$ & 16 & 16 & 11 & $\begin{array}{c}(0.92-0.98) \\
\text { Sensitivity } \\
0.69\end{array}$ \\
$\begin{array}{l}\text { PRRS-US infected } \\
(2 \text { herds) }\end{array}$ & 81 & 81 & 46 & $\begin{array}{c}0.41-0.89) \\
0.57\end{array}$ \\
$\begin{array}{l}\text { Double infected } \\
\text { herds }{ }^{\mathrm{a}}(2 \text { herds) }\end{array}$ & 61 & 61 & 46 & $\begin{array}{c}(0.45-0.68) \\
0.75\end{array}$ \\
\hline
\end{tabular}

a PRRS-EU and PRRS-US infected herds.

${ }^{\mathrm{b}}$ Confidence interval.

Table II. Indirect ELISA test results in meat juice samples from herds with known PRRS status (Study 2). Herd tests performed on blood samples assessed herd infection statuses using serological tests capable of differentiating the type of the PRRSV strain.

\begin{tabular}{lccc}
\hline Herd infection status & $\begin{array}{c}\text { Number of } \\
\text { herds }\end{array}$ & $\begin{array}{c}\text { Number of } \\
\text { samples }\end{array}$ & $\begin{array}{c}\text { \% positive meat } \\
\text { samples (95\% C.I. }{ }^{b} \text { ) }\end{array}$ \\
\hline PRRS non-infected & 27 & 510 & $2.0(1.0-3.6)$ \\
PRRS-EU infected & 11 & 163 & $64(57-72)$ \\
PRRS-US infected & 15 & 188 & $44(36-51)$ \\
Double infected herds $^{\mathrm{a}}$ & 17 & 239 & $56(50-63)$ \\
\hline
\end{tabular}

a PRRS-EU and PRRS-US infected herds.

${ }^{\mathrm{b}}$ Confidence interval.

herd sensitivity related to the confidence limits of the within-herd prevalence estimate were $85.3 \%$ and $98.2 \%$, respectively. The probability of assigning a PRRS negative status to a PRRS non-infected herd was 99.97\% (Tab. IV) The lower and upper values of herd specificity related to the confidence limits of the test specificity estimate were $99.77 \%$ and $100.00 \%$, respectively. The herd-level negative predictive value was $99.9 \%$ and the herd-level positive predictive value was $97.4 \%$ (Tab. V). The herdlevel predictive value of PRRS suspect status was $55 \%$ which means that there was a $55 \%$ probability that a herd assigned a PRRS suspect status would turn out PRRS positive (Tab. VI).

\subsection{Validation of the meat sample system's PRRS status assignment (study 4)}

PRRS suspect status was assigned to a total of 89 herds in the validation phase. Forty-nine out of the 89 herds accepted to participate in a follow-up blood sample study and at the same time continue the meat sample monitoring of the herd. Herds that participated in the study seemed comparable 
Table III. Binomial probabilities of herd test results in 10 meat samples.

\begin{tabular}{lcc}
\hline $\begin{array}{l}\text { Meat juice } \\
\text { herd test result }\end{array}$ & PRRS infected herds & PRRS non-infected herds \\
\hline PRRS suspect & ${ }^{a} \mathrm{P}\{Y \geq 2 \mid Y \in \operatorname{bin}(10 ; 0.44)\}=0.973$ & $\mathrm{P}\{Y \geq 2 \mid Y \in \operatorname{bin}(10 ; 0.02)\}=0.016$ \\
PRRS negative & $1-\mathrm{P}\{Y \geq 2 \mid Y \in \operatorname{bin}(10 ; 0.44)\}=0.027$ & $1-\mathrm{P}\{Y \geq 2 \mid Y \in \operatorname{bin}(10 ; 0.02)\}=0.984$ \\
\hline
\end{tabular}

${ }^{\text {a }} \mathrm{P}\{Y \geq a \mid Y \in \operatorname{bin}(b ; p)\}$ is the binomial probability that $a$ samples or more are positive when $b$ samples are tested and each sample has a probability $p$ of being positive.

Table IV. Herd level sensitivity and herd level specificity of the meat sample herd test. The herd test was based on 10 meat juice samples with 10 additional samples collected in herds with two or more positive samples among the first 10 samples.

\begin{tabular}{lcc}
\hline $\begin{array}{l}\text { Meat juice herd } \\
\text { test result }\end{array}$ & PRRS infected herds & PRRS non-infected herds \\
\hline PRRS positive & ${ }^{a} \mathrm{P}\{Y \geq 2 \mid Y \in \operatorname{bin}(10 ; 0.44)\}^{2}=0.947$ & $\mathrm{P}\{Y \geq 2 \mid Y \in \operatorname{bin}(10 ; 0.02)\}^{2}=0.0003$ \\
PRRS negative & $1-\mathrm{P}\{Y \geq 2 \mid Y \in \operatorname{bin}(10 ; 0.44)\}^{2}=0.053$ & $1-\mathrm{P}\left\{Y \geq 2 \mid Y \in \operatorname{bin}(10 ; 0.02\}^{2}=0.9997\right.$ \\
\hline $\begin{array}{l}\text { a } \mathrm{P}\{Y \geq a \mid Y \in \operatorname{bin}(b ; p)\} \text { is the binomial probability that } a \text { samples or more are positive when } b \text { samples are } \\
\text { tested and each sample has a probability } p \text { of being positive. }\end{array}$
\end{tabular}
tested and each sample has a probability $p$ of being positive.

Table V. Positive and negative predictive values of the meat sample herd test result in 10 samples with 10 additional samples collected in herds with two or more positive samples among the first 10 samples. Two thousand herds were monitored in the test and $2 \%$ of the herds $(n=40)$ were assumed to be infected. The predictive value of a PRRS positive herd test result was $38 / 39=0.974$. The predictive value of a PRRS negative herd test result was 1959/1961 $=0.999$.

\begin{tabular}{lccc}
\hline Meat sample herd test result & PRRS infected herds & PRRS non-infected herds & \\
\hline PRRS positive & 38 & 1 & 39 \\
PRRS negative & 2 & 1959 & 1961 \\
\hline & 40 & 1960 & 2000 \\
\hline
\end{tabular}

Table VI. Predictive value of a meat sample PRRS suspect herd test result in 10 samples. Two thousand herds were monitored in the test and $2 \%$ of the herds $(n=40)$ were assumed to be infected. The predictive value of a PRRS suspect herd test result was $39 / 71=0.55$.

\begin{tabular}{lccc}
\hline Meat sample herd test result & PRRS infected herds & PRRS non-infected herds & \\
\hline PRRS suspect & 39 & 32 & 71 \\
PRRS negative & 1 & 1928 & 1929 \\
\hline & 40 & 1960 & 2000 \\
\hline
\end{tabular}


to the herds that did not participate. Two herds were excluded from the study because the blood samples had not been collected according to instructions. The results of the blood samples conformed to the findings of the meat juice samples at the herd level. Twenty-nine out of 47 herds $(62 \%)$ were assigned a PRRS positive status by both systems (Tab. VII). All of the remaining herds $(n=18)$ were PRRS negative by both systems. The confidence interval for the herd positive predictive value was $0.88-1.0$. The confidence interval for the herd negative predictive value was $0.81-1.0$. The predictive value of a PRRS suspect status was 0.62 (C.I.: 0.46-0.76).

Twenty-two out of the 29 PRRS positive herds were infected with PRRS-EU and 7 herds with PRRS-US. None of the herds were infected with both types of PRRSV. In herds infected with PRRS-EU, 57\% of the samples were positive by the meat sample test. In herds infected with PRRS-US, $34 \%$ of the samples were positive. The number of (false) positive samples from
PRRS negative herds in the validation study was $2.3 \%$ (Tab. VIII).

\section{DISCUSSION}

The proportions of false positive samples in study 2 and study 4 were $2.0 \%$ and $2.3 \%$, respectively. This corresponded to a test specificity of approximately 0.98 . The specificity of the test estimated from the panel of paired samples was 0.96 and thus slightly lower, but the confidence intervals overlapped. Concerning the proportion of positive samples in infected herds, the results obtained in the validation phase were in accordance with the findings of the study 2: PRRS-EU infected herds had the highest apparent prevalence in the meat sample system (study 4: 57\%; study 2: $64 \%$ ). In PRRS-US infected herds, the apparent prevalences in study 4 and 2 were $34 \%$ and $44 \%$.

The theoretical link between the herd and individual test performance characteristics

Table VII. Validation of the meat sample herd test result by blood sample herd test results.

\begin{tabular}{lcc}
\hline $\begin{array}{l}\text { Meat sample } \\
\text { herd test result }\end{array}$ & \multicolumn{2}{c}{ Blood sample herd test result } \\
\cline { 2 - 3 } & PRRS positive & PRRS negative \\
\hline PRRS positive & 29 & 0 \\
PRRS negative & 0 & 18 \\
\hline
\end{tabular}

Table VIII. Indirect ELISA test results in meat juice samples from herds with known PRRS status (Study 4). Herd tests performed on blood samples assessed herd infection statuses using serological tests capable of differentiating the type of PRRSV strain.

\begin{tabular}{lccc}
\hline $\begin{array}{l}\text { Herd infection } \\
\text { status }\end{array}$ & Number of herds & Number of samples & $\begin{array}{c}\text { \% positive meat } \\
\text { samples }(95 \% \text { C.I }\end{array}$ \\
\hline PRRS non-infected & 18 & 435 & $2.3(1.1-4.2)$ \\
PRRS-EU infected & 22 & 491 & $57(53-61)$ \\
PRRS-US infected & 7 & 146 & $34(27-43)$ \\
\hline
\end{tabular}

${ }^{\mathrm{a}}$ Confidence interval. 
can be developed by considering the linear relationship between apparent within-herd prevalence (AP), true prevalence (TP), and the effect of test sensitivity (Se) and test specificity ( $\mathrm{Sp}$ ) on this relationship:

$$
\mathrm{AP}=(1-\mathrm{TP}) \times(1-\mathrm{Sp})+\mathrm{TP} \times \mathrm{Se}
$$

From the equation it follows that for a non-infected herd (TP $=0$ ), AP (or the probability of a positive test result $)=1-\mathrm{Sp}$. For an infected herd (TP $>0$ ), the probability that a randomly selected animal will test positive equals AP where AP is a function of test sensitivity, test specificity and true prevalence.

We studied the within-herd prevalence in 1603 infected herds and found that the proportion of blood sample blocking ELISA positive finishing pigs was 0.83 as an indication of high prevalence in this age-group (B. Strandbygaard, unpublished data). Given the test sensitivities estimated in study 1 , the apparent prevalences found in study 2 were in accordance with a high true prevalence in slaughter pigs.

The herd level test result in the meat juice indirect ELISA was also affected by sample size and the number of positive samples used to define a positive herd. In noninfected herds, AP $=1-\mathrm{Sp}$. If we assume that $\mathrm{Sp}$ is a constant value for all animals in the herd, the probability of finding at least 1 positive individual (false-positive herd proportion $=1-$ herd specificity) is $1-(\mathrm{Sp})^{n}$, where $n$ is the number of animals tested. If sample size increases, the falsepositive herd proportion also increases (herd specificity decreases). If more than 1 positive sample is required as a herd cutoff, the false-positive herd proportion is reduced (herd specificity increases). In infected herds, the probability that a randomly selected animal will test negative equals 1 - AP. If we assume that test sensitivity and test specificity are constant for all animals in the herd, the probability of finding 0 positive individuals (false-negative herd proportion $=1-$ herd sensitivity) equals $(1-\mathrm{AP})^{n}$. The false-negative herd propor- tion increases (herd sensitivity decreases) by increasing the herd cut-off. So, there is an inverse relationship between herd sensitivity and herd specificity at a fixed sample size depending on the herd positive cutoff. As a result of the test's (sub-optimal) specificity, PRRS negative herds must expect that on average every 50th sample is positive. The use of one positive sample as the herd positive cutoff at a sample size of 10 samples per three months was unacceptable, because the false-positive herd proportion would then be $1-0.98^{10}=0.18$ and approximately 0.55 at the annual level ${ }^{1}$. The false-positive herd proportion was reduced to 0.016 by increasing the cutoff to 2 positive samples and $97.3 \%$ of infected herds would be detected (equivalent to the calculations in Tabs. II and V). The herd specificity value was still considered too low, so we decided to collect 10 additional samples as soon as we found two positive samples among the first 10 samples (= PRRS suspect herd). This procedure allowed us to increase the herd specificity even further (0.9997), while maintaining the herd sensitivity at almost the same level (Tabs. III and IV). The effect of increasing the herd cut-off on the herd sensitivity, herd specificity and expected numbers of false-positive and false-negative herd tests has been summarized in table IX. It appears from the table, that the smallest number of misclassifications is expected at a herd cut-off of 2 positive samples.

When a herd was assigned a PRRS suspect status, there still was a $45 \%$ chance $(100 \%-55 \%)$ that this event was a "false alarm" (study 3, Tab. VI). The level of this probability was confirmed in study 4 , since 18 herds out of 47 herds $(38 \%)$ were noninfected. However, the herd-level positive and negative predictive values of the meat sample system were high (0.974 and 0.999, respectively) and were confirmed in study 4 where the findings of the meat sample

${ }^{1} 1-(1-0.18)^{4}=0.55$. 
Table IX. The effect of herd cut-off on the herd sensitivity, herd specificity and the numbers of false-positive and false-negative herd tests by meat juice surveillance.

\begin{tabular}{lcccc}
\hline Herd cut-off & $\begin{array}{c}\text { Herd } \\
\text { sensitivity }\end{array}$ & $\begin{array}{c}\text { Number of } \\
\text { false-negative herds }^{a}\end{array}$ & $\begin{array}{c}\text { Herd } \\
\text { specificity }\end{array}$ & $\begin{array}{c}\text { Number of } \\
\text { false-positive herds }\end{array}$ \\
\hline 1 & 0.997 & 0 & 0.9665 & 66 \\
2 & 0.973 & 2 & 0.9997 & 1 \\
3 & 0.889 & 8 & 1.0 & 0 \\
\hline
\end{tabular}

a Assumption: $2 \%$ truly infected herds among 2000 herds.

system were in accordance with the results obtained by the serological analysis of blood samples from the herds.

\section{False-negative and false-positive herd} tests. Blood sample collection in herds for herd infection status monitoring by serology is usually done at annual intervals or at the occurrence of clinical signs in the herd. Continuous monitoring of a herd thought to be disease negative holds potential benefits because silent infections are possibly detected earlier with this system. Methods to detect the change in rate of positive samples reflecting a change in disease status of a herd from negative to positive needs to be developed. We chose to create a model of change in herd disease statuses based on the results of a sequence of 10 samples because this approach allowed us to use well-known methods for herd test interpretation and estimate herd sensitivity, herd specificity and herd predictive values. The probability of a false-positive herd test result in the meat sample test system was 0.0003 . This probability seemed very low, but calculated on an annual basis (4 times 10 samples) the probability was $0.0012^{2}$. The positive predictive value was 0.974 , that is, approximately 3 out of 100 positive herd diagnoses were expected to be false-positives. This probability is not acceptable because the herd owner may start to bring in PRRS positive animals in his negative herd and because herd owners and herd veterinarians will not accept a new diagnostic method with substantial less quality than the alternative: out of 31,109 herd tests based on blood samples from 1994 to 1998, we have no knowledge of a false-positive herd result (using two positive blood samples as a cutoff for herd positive status). We consequently advise herd-owners to confirm a PRRS positive herd test result in the meat sample test system by blood samples.

The challenge of the meat sample test system is to avoid false-negative herd tests. The herd sensitivity based on 10 samples (3 months of monitoring) was estimated at 0.947. Based on 6 months of monitoring (two times 10 samples) the probability of a false-negative test result was down to $0.0028^{3}$. False-negative herd tests in the meat sample test system were occasionally discovered in herds thought to be negative but with clinical signs consistent with PRRS and PRRSV infection diagnosed by virus isolation or detection of antibodies in blood samples. The assumptions underlying the herd sensitivity estimate were that the within-herd apparent prevalence would jump from zero to 0.44 within a limited time period following the infection of a previously PRRSV negative herd and that withinherd apparent prevalences were binomial

$3(1-0.947)^{2}=0.0028$.

$21-(1-0.0003)^{4}=0.0012$. 
distributed. Neither of these assumptions were satisfied. It may be speculated that one to two months may have passed from introduction of infection in a herd until the within-herd prevalence reached detectable levels. We accounted for the effect of nonbinomial distribution of apparent prevalences in PRRS-EU and double infected herds by using the conservative estimate 0.44 . We saw that some herds had apparent prevalences below $40 \%$. But even with an apparent prevalence of $25 \%$, the probabilities of detection of infection within 3 months and 6 months were $0.571^{4}$ and $0.815^{5}$, respectively.

Whether or not the monitoring scheme will succeed in reducing the inter-herd dissemination of the virus includes more issues than the testing itself. The within-herd dynamics of the infection and the number of herds in contact with infected herds between the moment of virus introduction and the diagnosis are important aspects. In newly PRRS infected herds, the virus is suspected to spread to pigs of any age within few weeks, possibly with the exception, that the infection may spread at a slower pace in age-segregated production systems. Transport of feeder pigs from a newly infected herd to other herds usually occurs weekly or bi-weekly. No serological surveillance programme will be able to prevent inter-herd transmission in this situation. An estimated $75 \%$ of feeder pigs in Denmark are sold on one-year contracts between two farmers. The potential benefit of the monitoring system is the prevention of transmission when suppliers of feeder pigs make new contracts with other farmers and when occasional surpluses of feeder pigs are sold in the open marked as presumed noninfected animals.

In conclusion, an acceptable herd-level classification of PRRSV infection status can be achieved using this system. It requires,

\footnotetext{
${ }^{4} \mathrm{P}\{Y \geq 2 \mid Y \in \operatorname{bin}(10 ; 0.25)\}^{2}=0.571$.

$51-[1-0.571]^{2}=0.815$.
}

however, that the veterinary and farmer communities adapt an understanding that false positive samples may occur relatively frequently, and that they may be tolerated at a low level without jeopardising herd health monitoring.

\section{REFERENCES}

[1] Albina E., Leforban Y., Baron T., Plana J., Vannier P., An enzyme linked immunosorbent assay (ELISA) for the detection of antibodies to the porcine reproductive and respiratory syndrome (PRRS) virus, Ann. Rech. Vet. 23 (1992) 167-176.

[2] Armitage P., Berry G., Statistical Methods in Medical Research, third edition, Blackwell Science, Oxford, 1994.

[3] Bøtner A., Strandbygaard B., Sørensen K.J., Have P., Madsen K.G., Madsen E.S., Alexandersen S., Appearance of acute PRRS-like symptoms in sow herds after vaccination with a modified live PRRS vaccine, Vet. Rec. 141 (1997) 497-499.

[4] Dee S., Collins J., Halbur P., Keffaber K., Lautner B., McCaw M., Polson D., Rodibaugh M., Sanford E., Yeske P., Control of porcine reproductive and respiratory syndrome (PRRS) virus, Swine Health Prod. 4 (1996) 95-98.

[5] Le Potier M.F., Fournier A., Houdayer C., Hutet E., Auvigne V., Hery D., Sanaa M., Toma B., Use of muscle exudates for the detection of anti-gE antibodies to Aujeszky's Disease virus, Vet. Rec. 143 (1998) 385-387.

[6] Martin W.S., Shoukri M., Thorburn M.A., Evaluating the health status of herds based on tests applied to individuals, Prev. Vet. Med. 14 (1992) 33-43.

[7] McCaw M.B., Effect of reducing crossfostering at birth on piglet mortality and performance during an acute outbreak of porcine reproductive and respiratory syndrome, Swine Health Prod. 8 (2000) 15-21.

[8] Mortensen S., Strandbygaard B., Herd-level criteria for European and American PRRSV subtype status based on serology, Proceedings of the 16th Congress of the International Pig Veterinary Society, 17-20 September 2000, Melbourne, Australia, p. 584.

[9] Mousing J., Thode-Jensen P., Halgaard C., Bager F., Feld N., Nielsen B., Nielsen J.P., Bech-Nielsen S., Nation-wide Salmonella enterica surveillance and control in Danish slaughter swine herds, Prev. Vet. Med. 29 (1997) 247-261.

[10] Murtaugh M.P., Elam M.R, Kakach L.T., Comparison of structural protein coding sequences of 
the VR-2332 and Lelystad virus strains of the PRRS virus, Arch. Virol. 140 (1995) 1451-1460.

[11] Nelson E.A., Christoffer-Jennings J. Drew T., Wensvoort G., Collins J.E., Benfield D.A., Differentiation of United States and European strains of porcine reproductive and respiratory syndrome virus by monoclonal antibodies, J. Clin. Microbiol. 31 (1993) 3184-3189.

[12] Nielsen B., Ekeroth L., Bager F., Lind P., Use of muscle fluid as a source of antibodies for detection of salmonella infection in slaughter pig herds, J. Vet. Diagn. Invest. 10 (1998) 158-163.
[13] Sørensen K.J., Strandbygaard B., Bøtner A., Madsen E.S., Nielsen J., Have P., Blocking ELISA's for distinction between antibodies against European and American strains of porcine reproductive and respiratory syndrome (PRRS) virus, Vet. Microbiol. 60 (1998) 169-177.

[14] Wensvoort G., De Kluyver E.P. Luijtze E.A., Den Besten A., Harris L., Collins J.E., Christianson W.T.,Chladek D., Antigenic comparison of Lelystad virus and swine infertility and respiratory syndrome (SIRS) virus, J. Vet. Diagn. Invest. 4 (1992) 134-138. 